\title{
Revista Brasileira de Enfermagem REBEn \\ Reflexão na abordagem psicanalítica das representações do enfermeiro sobre si e sobre a Enfermagem
}

\author{
Reflections on the psychoanalytic representations of nurses about themselves and about \\ Nursing
}

Reflexión de la perspectiva psicanalistica de las representaciones del enfermero sobre si y sobre la Enfermería

\section{Marta de Oliveira Pimentel}

Mestre em Enfermagem, Docente da Escola de Enfermagem da Universidade Federal de Minas Gerais, Belo Horizonte, MG. mpimentel@ufmg.br

Daclé Vilma Carvalho

Doutora em Enfermagem, Docente da Escola de Enfermagem da Universidade Federal de Minas Gerais, Belo Horizonte, MG.

Parte derivada da dissertação de Mestrado: "Reflexão numa abordagem psicanalítica das representações oferecidas pelo enfermeiro sobre si e sobre a enfermagem". Curso de pós-graduação da Escola de Enfermagem da Universidade Federal de Minas Gerais

\section{RESUMO}

Trata-se de reflexões das representações do enfermeiro sobre si e sobre enfermagem, dentro do referencial psicanalítico da constituição do sujeito no âmbito do desejo que o anima, nas instâncias do imaginário e do simbólico. A análise pautou-se pelas práticas discursivas de Spink, com a utilização de associações de idéias na tradição hermenêutica. Entrevistou-se oito enfermeiros cujas representações foram dispostas em gráficos e quadros. Da análise dos discursos emergiram significados, da esfera simbólica, de produção de sentido. Pode-se apreender que o desejo do enfermeiro se apresenta como desejo do desejo do outro, um desejo imaginário e por constituir-se. Esse objeto que se apresenta identificado ao eu podese apresentar idealizado, supervalorizado ou banalizado, depreciado ou punitivo. Nessa perspectiva, novos horizontes poderão se abrir no que tange à formação e à prática profissional do enfermeiro, portador de um sentido que Ihes possibilitem perceberem-se como sujeitos na sua expressividade profissional. Descritores: Enfermeiro; Enfermagem; Psicanálise.

\section{ABSTRACT}

This study describes some reflections on the representations of nurses about themselves and about nursing, in order to analyze them within a psychoanalytic framework of the constitution of the subject in the sphere of the desire which motivates them, at the levels of the imaginary and the symbolic. The analysis adopted was the discursive practices proposed by Spink, using association of ideas in the hermeneutical tradition. Considering the subject, eight nurses were interviewed whose interpretations were displayed on graphs and tables. From discourse analysis emerged meanings in the symbolic sphere and the production of meanings. It is possible to understand that the desire of the nurse shows itself as the desire of others' desire, an imaginary desire and therefore, it is imaginary and to be constituted. This object which appears identified with the self, may appear over-valued or commonplace, depreciated or punished. From this point of view, new horizons may open up in practice and professional training for nurses, which brings them together around a signifier which can give them a meaning, enabling them to see themselves as subjects in their professional expressiveness.

Descriptores: Nurse; Nursing; Psycoanalysis.

\section{RESUMEN}

Se trata de reflexiones acerca de las representaciones del enfermero sobre si y la enfermería, adentro del referencial psicanalítico de la constituición del sujeto en el ámbito del deseo que lo anima, en las instancias del imaginario y del simbólico. El análisis adoptada fue de las prácticas discursivas propuesta por Spink, com la utilización de asociaciones de ideas en la tradición hermenéutica. Fueron entrevistados ocho enfermeros cuyas representaciones han sido puestas en gráficos y cuadros. Del análisis de los discursos surgieron significados de la esfera simbólica, de producción de sentido. Se puede aprehender que el deseo del enfermero se presenta como el deseo del deseo del outro, un deseo imaginario, y, por integrarse. Eso objeto que se apresenta identificado al yo, puede presentarse idealizado, supervalorado o banalizado, rebajado o punitivo. En esa perspectiva, nuevos horizontes podrán abrirse en lo que se refiere a la formación y la práctica profesional del enfermero, portador de um sentido que le dé la posibilidad de verse como sujetos en su expresividad profesional.

Descriptores: Enfermero; Enfermería; Psicoanálisis.

Pimentel MO, Carvalho DV. Reflexão na abordagem psicanalítica das representações do enfermeiro sobre si e sobre a Enfermagem. Rev Bras Enferm 2006 nov-dez; 59(6): 780-6.

\section{DOS (IN)CÔMODOS QUE CONDUZIRAM AO TEMA}

Ao considerarmos os caminhos evolutivos da enfermagem e sua vinculação estreita com os postulados a de quem é cuidado e de regras, normas e procedimentos rígidos, morais e técnicos no desenvolvimento 
posterior da enfermagem, esses elementos podem ter sido geradores de atitudes ambíguas no campo da saúde e de conflitos entre os próprios profissionais enfermeiros. Na convivência com os mesmos, pudemos perceber os conflitos nos embates profissionais cotidianos que ora os levam a exacerbar a onipotência da enfermagem/enfermeiro, ora os jogam na impotência. Estes conflitos eram repetidamente verbalizados, sentidos e somatizados. Entretanto, o que nos incomodava era a percepção de que, mesmo frente a essa angústia, não se conseguia mobilização suficiente para a busca de saídas dessa situação como se a comodidade ainda fosse o refúgio mais seguro frente ao incômodo. Provavelmente deveria haver algum ganho, psicologicamente falando, que os mantinha nessa posição. Neste sentido, surgiram as indagações: quais seriam as representações que teria esse profissional sobre si mesmo? Qual o discurso desses enfermeiros sobre a enfermagem? Quais seriam as suas representações da enfermagem?

O desconforto sentido levou-nos a interlocução com outras áreas do conhecimento como a Psicologia, o que se configurou como de grande importância, pois percebemos que o próprio profissional se autoriza a ser 0 que é, num continuum processual de vida frente às contingências do seu contexto histórico-social, buscando formas de superação. Ele busca reconhecer o seu desejo e o lugar onde ele se encontra, visto que é desse mesmo lugar que ele se projetará enquanto sujeito e poderá ser reconhecido no seu desejo. Foi pensando neste indivíduo, na sua singularidade, que optamos por trabalhar com a psicanálise como orientação teórica que norteasse o estudo.

Ao se buscar instrumetalizar o nosso saber e as formas do conhecer-se com outros aportes teóricos, enfoca-se a importância do autoconhecimento como fator minimizador do sofrimento psíquico das pessoas humanas tendo em vista um re-investimento de suas potencialidades frente às transformações sociais que estão ocorrendo, particularmente no âmbito da saúde, no qual o enfermeiro vem sendo convocado a assumir posições de liderança, o que pressupõe posicionamentos ético-político-filosóficos mais consistentes.

Assim, este estudo tem como objetivo analisar as representações do sujeito enfermeiro sobre si e sobre a enfermagem, dentro do referencial teórico psicanalítico da constituição do sujeito no âmbito do desejo que o anima, nas instâncias do imaginário e do simbólico.

\section{MARCO REFERENCIAL PSICANALÍTICO}

A psicanálise se mostra como uma teoria e uma prática, que pretende falar do homem enquanto ser singular, mesmo afirmando a sua clivagem, deixando a subjetividade de ser entendida como um todo unitário, identificado com a consciência, para ser uma realidade dividida em dois sistemas - o inconsciente e o consciente. $O$ propósito da psicanálise é explicitar a lógica do inconsciente e o desejo que a anima ${ }^{(1)}$. O sujeito, no sentido freudiano é o sujeito do inconsciente. Aquestão do sujeito se coloca entre o sujeito do inconsciente, je (eu), o sujeito por excelência, que deve advir no lugar do isso (id) e o moi (eu) a função imaginária do sujeito ${ }^{(2)}$.

O Sujeito Humano percorre uma trajetória para se constituir que se inicia com uma ausência de representação sobre si mesmo, encontra-se indiferenciado e em um estado de pura excitabilidade instintual (algo não psíquico). Assim, uma das primeiras investidas neste processo de diferenciação consiste na representabilidade pulsional. A pulsão existe só e unicamente porque se representa, portanto esta "energia" existe pela representação ${ }^{(3)}$. $A$ representação (Vorstellung) é o elemento constituinte da vida mental e pode tornar-se consciente ou ser inibida, mantida fora do sistema pré-consciente/ consciente, pela via do recalcamento. Esta se dá pelos seus representantes: o ideativo (Vorstellung Repräsentant) e o afeto (Affekt), ambos representantes psíquicos da pulsão (Psychischerepräsentanz), ou seja, a representação da representação psíquica ${ }^{(1)}$. 0 afeto (Affekt) é a expressão qualitativa da quantidade de energia pulsional. Os destinos do afeto são produzidos mediante transformações do mesmo na histeria de conversão, deslocamento (nas obsessões) e troca de afeto nas neuroses de angústia e melancolia ${ }^{(4)}$.

O recalcamento (Verdrängung) é um processo pelo qual a subjetividade do indivíduo é clivada em instâncias distintas, sistema inconsciente e o préconsciente/consciente. Sua essência consiste no fato de afastar determinada representação do consciente, mantendo-a distante. Esta representação ou idéia ameaçadora é mantida no sistema inconsciente através da censura exercida pelo ego por despertar sentimentos de vergonha e de dor ${ }^{(5)}$. A impossibilidade de uma conciliação entre uma representação ou grupo de representação e o ego, constitui a defesa e transforma o ego em sujeito de operação defensiva. Todo desprazer neurótico é um prazer que não pode ser sentido como tal, sendo sentido pelo ego como desprazer, ou seja, sofreu processo de recalcamento, mas conseguiu chegar por caminhos indiretos a uma satisfação direta ou substitutiva(6)

As percepções inconscientes são absolutamente inatingíveis, só as conhecemos enquanto representadas. Essas percepções são denominadas por Freud de "pensamentos". Pela existência da representação de palavra é que podemos conhecer as tramas dessas percepções que nos escapam. É, "a palavra que dota os investimentos da qualidade de representação, qualidade essa impossivel de ser tirada das próprias percepções"(3). A palavra confere um caráter de representatividade aos atos de investimentos pulsionais do sujeito. Para Lacan, é a palavra que barra o gozo (da pulsão) e a linguagem o que introduz o indivíduo humano no registro simbólico. O indivíduo suporta o campo da realidade, via uma representação fantasmática pois, o afeto (Affekt), por não ser passivel de recalcamento, existe e insiste em se representar, exigindo do sujeito uma representação significante.

Assim, o que se busca e o que se procura satisfazer via essa representação fantasmática (imaginária) é uma satisfação pulsional que não se realizou e que independe de um objeto concreto. Esse Sujeito, ao barrar o gozo, institui o real, mas fica permanentemente ligado a essa representação fantasmática, se constitui como um sujeito causado pelo outro (objeto fantasmático-imaginário) ao se formular na demanda da pulsão e ao se articular no fantasma do objeto de desejo (nome do pai, supereu, ideal do eu) ele também se apaga, apoiandose no sintoma ${ }^{(3)}$.

Em seu texto, Inibição, Sintoma e Angústia, Freud, fala que "O sintoma é o resultado de uma satisfação pulsional que não se realizou"(7), e denuncia o fracasso do recalque, ele (o gozo) retorna na sua forma de insatisfação, dor, angústia, ou seja, em forma de sintoma, que existe e insiste no recalque pela palavra, na representação significante enquanto constitutiva de vida interrogativa. "O sintoma é uma saída de saúde, momentânea, precária, mas a única que pode garantir certa ordem do sujeito"(3). Todo ser humano como sujeito se caracteriza pelo sintoma, pelas suas coincidências, coisas que incidem juntos. "É por coincidência que eu sou eu" (Lacan). O sintoma seria "o quarto termo que amarraria numa intersecção de fundo, o real, o imaginário e o simbólico"(3).

O sujeito se constitui pelas três vertentes da interseção do real, do imaginário e do simbólico, e o sintoma seria o lugar de expressão desse real e do imaginário buscando se representar, pois "o real suporta a fantasia e a fantasia protege o real"(2). Assim, o eu humano se constitui sobre o fundamento da relação imaginária que contém a pluralidade do vivido. Adimensão imaginária articula-se ao simbólico por uma das suas vertentes.

O eu (moi) está estruturado exatamente como um sintoma, é o sintoma humano por excelência. "O absurdo fundamental do comportamento interhumano só é compreensível em função deste sistema, denominado por Melaine Klein, o eu humano, esta série de defesas, de negações, de barragens, de inibições, de fantasias fundamentais, que orientam e dirigem o sujeito"(8).

O sintoma, como o significante (modo de expressão do sujeito) representa o próprio sujeito, mas é a recusa desse sentido pelo sujeito que lhe coloca um problema. Assim sendo, "Atrás de cada sintoma só e sempre está o sujeito" e o advir desse sujeito deve comportar a reintegração de sua história e sua assunção, mesmo que se traduza na possibilidade de convivência com o sintoma.

A angústia é a condição soberanamente humana do homem na terra, elaé estrutural e estruturante e revela a impotência de significante à vertente imaginária, a presença do desejo do outro causando a minha vida (a - fórmula 
do fantasma) portanto, esse desejo do outro não representado eclipsa o sujeito desejante.

A angústia do sujeito é a interrogação do ponto negro, da "sombra", do "fantasma": "Che vuoi?" Que Queres? Ou seja, o quê quer ele de mim? Eu não sei o que esse outro quer, mas também não posso sabê-lo, pois isso seria defrontar-me com a castração, a falta, assim, fico tributário do "bem querer" do outro, e essa situação é geradora de angústia. Essa pergunta endereçada ao desejo do outro vem como resposta. Ela interroga o próprio sujeito quanto ao seu desejo e o coloca frente ao real da falta, da impossibilidade do ter. "Lá onde eu tenho medo eu desejo" (Lacan).

O desejo alienado no desejo do Outro só pode libertar-se na medida que, o outro desapareça como suporte do desejo do sujeito, é a destruição desse Outro que possibilitará a constituição do sujeito desejante, pois, se essa relação se mantiver, não somente é impossível a constituição do sujeito como sujeito autônomo, como também se falar em subjetividade individual. $O$ desejo permanece marcado pela sua função negatriz, o desejo de um necessariamente se aliena no desejo do outro (concepção Hegeliana da dialética do Senhor e do Escravo). A saída deste tipo de relação se encontra na possibilidade de assunção ao simbólico. "É através do simbólico, da linguagem, que o desejo vai entrar numa relação de reconhecimento recíproco, na troca simbólica do eu e do tu"(9)

Pelo ingresso no simbólico produz-se uma transformação no objeto através da linguagem. A concretude e o poder das palavras para Lacan é como "a roda de moinho por onde incessantemente o desejo humano se mediatiza, entrando no sistema de linguagem"(8). É o simbólico que garante a constituição do sujeito. "A palavra é a morte da coisa" (Lacan), e pela entrada no sistema simbólico, via linguagem o sujeito consegue se distanciar das suas vivências ("das coisas") via representação. Ao adentrar nesse universo simbólico o sujeito, mediatizado pela linguagem, perde-se na relação de si a si ("refenda") e se aliena no significante. O eu do sujeito passa a ser o lugar da mentira e do ocultamento, lugar da morte do sujeito do Inconsciente (Jê), que para a sua "revelação" necessitará de um resgate, pois se a palavra produz um corte no sujeito e garante a sua sobrevivência no social ela o aliena de si mesmo. "Pela palavra eu me encontro (sujeito do enunciado) e nela me perco (sujeito da enunciação)" (1:124-5; 190-3). A ordem simbólica é a ordem humana, transindividual na medida em que precede o sujeito. A linguagem se coloca numa relação de exterioridade em relação ao sujeito, ou seja, como um conjunto estrutural independente do indivíduo que fala, como o grande Outro.

E nesta aposta fálica, ao renunciar ao desejo de ser, em prol do desejo de ter (enquanto falta, vazio, buraco) o indivíduo se situa, segundo Lacan, numa encruzilhada estrutural de amplas conseqüências, que se fracasse (introdução de processos psicóticos) que se tenha sucesso, como algo que aliena 0 desejo do sujeito na dimensão da linguagem ao instituir uma estrutura de divisão subjetiva, ele se separa de uma parte de si mesmo ${ }^{(10)}$. Assim, "o que o sujeito não sabe é sobre o seu desejo", pois o mesmo encontra-se entre as vicissitudes da demanda e a exigência de amor, nesta hiância em que se situa a experiência do desejo, apreendida no início como desejo do outro, e no interior da qual, o sujeito tem de situar seu próprio desejo.

\subsection{Das expressões representativas do sujeito}

A análise se processa numa produção de sentido em posição epistemológica definida aqui em termos de processos e produção. Desse modo, "aprofundase no mundo subjetivo dos sujeitos na busca das representações que orientam suas ações e suas relações humanas"(11). Este estudo fez uso das práticas discursivas para a apreensão do conhecimento dado pelos sujeitos pesquisados $^{(11)}$. Reconhece-se desta forma a polissemia intrínseca às práticas discursivas. Estas práticas têm um caráter essencial de discurso, e este termo, "designa de um modo rigoroso e sem ambigüidades, a manifestação da língua na comunicação viva. Implica a participação do sujeito na sua linguagem através da fala do indivíduo"(12). A mensagem destinada ao outro é, num certo sentido, destinada em primeiro lugar ao mesmo que fala, donde se conclui que: falar é falar-se.
O discurso provoca a emergência da subjetividade e é nesta instância em que o "eu" designa o locutor, que o mesmo se enuncia como "sujeito". O eu se refere ao ato de discurso individual no qual é pronunciado e "é verdade ao pé da letra que o fundamento da subjetividade está no exercício da língua, não há outro testemunho objetivo da identidade do sujeito que não seja esse, que ele mesmo dá sobre si mesmo"(13).

Consideramos os discursos individuais dos enfermeiros, sujeitos da pesquisa, geradores das representações das quais eles são portadores. As representações são aqui consideradas como um produto que subsidia a análise do próprio processo de produção das mesmas, isto é, seus aspectos constitutivos, relevantes e reveladores de um sentido portado pelos discursos dos enfermeiros.

\section{PERCURSO METODOLÓGICO}

O percurso metodológico pauta-se no pressuposto de que conhecer é dar sentido ao mundo, é buscar entender a processualidade intrínseca da atividade de significação. Dar sentido é sempre uma atividade cognitiva, que implica na utilização de conexões neurais, habituais desenvolvida pela experiência no enquadre das contingências do contexto social e cultural, as quais pressupõem o tempo histórico e o tempo vivido subjetivamente e objetivamente nos processos de socialização primária e secundária. Os processos sóciocognitivos que sustentam o conhecimento não são autônomos, dependem intrinsecamente da história, seja no âmbito do indivíduo ou das formações discursivas próprias à cultura em que ele se insere.

A trajetória desta pesquisa iniciou-se com uma interpelação aos enfermeiros que se desdobrava em duas perguntas norteadoras: $O$ que vem à sua mente quando eu falo a palavra enfermeiro (a)? E o que lhe vem à mente quando eu falo a palavra enfermagem? Cada pergunta referia-se a um roteiro temático, que estava subdividido em dois blocos: Representações do enfermeiro sobre si e Representações do enfermeiro sobre a enfermagem.

Deste estudo participaram oito enfermeiros como sujeitos genéricos. Assim denominados na metodologia das práticas discursivas e se apresenta como: o indivíduo no grupo - sujeito da abordagem epistemológica do estudo das representações, é um símbolo vivo do grupo que ele representa - como o grupo no indivíduo, contanto que se tenha adequada compreensão do seu contexto social(14).

Uma primeira aproximação com os sujeitos genéricos foram os dados levantados na parte inicial da entrevista no intuito de apresentá-los, assinalando de quem são essas representações. São enfermeiras, na sua maioria mulheres casadas, inseridas nos diversos tipos de serviços de saúde e instituições universitárias, nos três níveis de atenção à saúde, desempenhando funções regulamentadas em Lei, com tempo igual ou superior a cinco anos no exercício profissional e numa faixa etária produtiva.

Os encontros para a realização das entrevistas foram acordados previamente e gravados após consentimento formal dos entrevistados através da assinatura do termo de esclarecimento e compromisso pós-informado. Foi utilizado como instrumento entrevistas semiestruturadas, individuais, baseadas nas associações de idéias. A entrevista iniciada após a introdução das perguntas norteadoras, foi se construindo a partir do conhecimento pré-reflexivo gerado na realidade experienciada pelos sujeitos pesquisados em direção a um conhecimento reflexivo, pois, a partir das primeiras associações efetivadas pelo enfermeiro, retornava-se à linguagem do discurso do sujeito, interpelando0, com o uso dos próprios termos na exposição das suas experiências (1as associações). Esse procedimento abria possibilidades para outras associações ou para re-significações das anteriormente dadas, pois o pesquisador vai procurando pistas que lhe permitam formular novas questões (Associações secundárias).

O modo de proceder descrito denomina-se, técnica de associação de idéia, "gera discursos que possibilitam acessar conteúdos compartilhadose narrativas voltadas ao posicionamento do eu"(11). Tem aderência ao manejo técnico da teoria psicanalítica que impõe uma regra fundamental, a da livre 
associação, "o fluir livremente das suas associações sobre um assunto que está sendo tratado no momento"(15). Essa técnica vem sendo utilizada em estudos centrados no processo de elaboração das representações, com o objetivo de entender as construções dos significantes utilizados pelo sujeito, na interface entre explicações cognitivas, investimentos afetivos e demandas derivadas das ações no cotidiano ${ }^{(11)}$.

Concluída a série de entrevistas, processou-se às transcrições, procurandose manter na integra a linguagem, as expressões utilizadas e as manifestações não verbais - risos, hesitações, ênfase das palavras, tom de voz, pausas (Associações Qualificadoras). Cada enfermeiro, sujeito genérico, desta pesquisa ganhou um nome substituto por respeito à sua identidade, pois, da sua subjetividade dão testemunho os discursos. Para organização e análise dos produtos buscou-se apreender as representações atribuídas pelos enfermeiros em relação aos roteiros temáticos: Representações do enfermeiro sobre si e Representações do enfermeiro sobre a enfermagem ${ }^{(14)}$.

Foram elaborados Mapas de associações de idéias nos quais foi transcrito o conteúdo integral de cada discurso, em quatro colunas distintas: Objeto, primeira associação, associações secundárias e associações qualificadoras. Isso permitiu apreender as representações, bem como as narrativas nas quais elas adquiriram significações (anexo 1). De cada discurso, elaborou-se gráficos das representações dos dois roteiros temáticos: Sobre o enfermeiro e sobre a enfermagem. Das representações apreendeu-se as significações reveladoras, delineando-se duas vertentes, do sujeito de quem se falava e do objeto do qual se falava, os quais foram transcritos em quadros (anexo 2).

Passou-se a seguir, à análise processual dos produtos dos discursos. As análises dos textos dos discursos engendraram novos textos que revelaram expressões significantes portadores de sentido representacional dos enfermeiros e elemento motriz dos seus desdobramentos, isto é, efeitos dos sujeitos na sua dimensão simbólica.

\section{RESULTADOS E DISCUSSÃO}

A) Salete, 41 anos de idade, enfermeira casada, está com quinze anos de exercício profissional. É coordenadora geral do serviço de enfermagem de uma instituição hospitalar de grande porte e, portanto, exercendo uma função administrativa relata a sua luta e sofrimento constantes para tornar a sua atividade algo grandioso aos olhos do outro. Eu achei que tinha de ser a mulher maravilha, tipo um espírito para estar em todos os lugares.

B) Alberto, 37 anos de idade casado, enfermeiro em exercício profissional há dez anos, exerce atualmente a função assistencial em uma unidade de internação de uma Instituição Hospitalar pública e fala do desconhecimento do seu desejo e da diferença do saber daquele que não é bem visto, nem bem vindo nos altos cargos do cenário político da saúde apesar de sua mestria e de ser um "expert" na assistência à saúde. Ser enfermeiro exige muito da gente porque é uma tarefa muito difícil, é um universo muito amplo.

C) Esmeralda, 51 anos de idade, casada, enfermeira docente, exerce a função educativa numa instituição universitária do setor privado. Está em exercício profissional há vinte e nove anos e relata a sua angústia em se ver como o negativo do retrato revelado do enfermeiro, daquele que sabe da enfermagem para negá-la na sua prática com uma vestimenta de profissional de nível superior - parecer/para ser enfermeiro, pois gravita a uma certa distância do outro que deveriam cuidar. Assim, mesmo com toda a vestimenta profissional não se conseguiu mudar a cultura social.

D) Violeta, 36 anos de idade, casada, enfermeira está em exercício profissional ha quatorze anos e atualmente, docente numa instituição universitária do setor privado, portanto, no desempenho de uma função educativa, fala da sua busca do objeto sedutor da enfermagem enquanto objeto desejável e desejante, que poderá sustentá-la na enfermagem como sujeito desejante. Uma profissão muito pouco sedutora, estática, que não reflete o cotidiano dela com as outras pessoas.

E) Carolina, 45 anos de idade, casada, enfermeira exerce função administrativa na gerência de serviço de enfermagem num estabelecimento de saúde da rede básica - nível secundário e é profissional há cerca de vinte anos. Ela fala sobre a enfermagem como a carreira que eu escolhi para vivenciar a minha vida profissional, da Enfermagem e de sua imagem pública, social e cultural banalizada, já que a sua prática é tida como aparentemente simples ao olhar do outro, muito elementar, um simples negociozinho. E de como o enfermeiro por medo ou timidez avaliza o mesmo discurso da banalização no seu cotidiano, que o puxa para baixo, ao desempenhar o "script" social que lhe deram, de estar sendo enfermeiro sem o ser realmente, apenas na aparência, na imagem, esperando que o outro lhe diga: Ah, você é demais!

F) Semíramis, 44 anos de idade, divorciada, é enfermeira há vinte anos, e atualmente, exerce a função educativa como docente numa instituição universitária do setor público. Relata aqui como aquilo que entrou acidentalmente na sua vida passou a ser vivida numa confusão de sentimentos no nível das emoções, no sentido do prazer e do desprazer que se destacam frente às situações dadas. E que a enfermagem, como profissão é expressão do sujeito e as suas perspectivas futuras é um enigma, pois dependem dos próprios sujeitos, estes que ainda estão em estado de sonolência, vivendo no instante mesmo do despertar.

G) Elba, 35 anos de idade, casada, é uma profissional enfermeira há nove anos. Atua na rede básica de saúde no nível secundário e sua função é assistencial. Ela fala como a enfermeira/enfermagem pode ser uma grande profissão desde que se comece a trabalhar com mais vontade, pois muitos enfermeiros ainda não despertaram para a enfermagem, para a abordagem cuidadosa do outro. Alguns sentem vergonha de cuidar.

H) Samantha, 31 anos de idade, solteira, é enfermeira há sete anos. Exerce a função assistencial num serviço de saúde, nível primário da rede básica. Fala aqui da sua intenção de ajudar o outro com o seu saber, das tentativas diárias de sustentar essa ajuda e do sofrimento que isso implica, pois há uma confusão no desempenho das ações do profissional no contexto organizacional das instituições de saúde e também no social, exigindo todo um esforço do mesmo para equacioná-la diante das demandas internas do sujeito. Ele vai se escondendo e se acostuma tanto com isso que não tem mais coragem de mostrar a potência do enfermeiro como profissional.

\section{CONSIDERAÇÕES FINAIS}

\section{Das nossas co-incidências}

Ao adentrar no momento mesmo de concluir, aludimos aos três tempos lógicos de Lacan - Olhar, compreender e concluir - que implicam a destruição subjetiva de representações, imagens que nos movem por meio de resignificações portadoras de significantes que possibilitem mudanças na posição subjetiva do sujeito perante o desejo, renomeando-o. Tendo em vista, que a problemática do sujeito consigo mesmo está em conjugação com o sentido do sintoma é a recusa desse sentido pelo sujeito que lhe coloca um problema, pois ao negar a reintegração de sua história e a sua assunção, isso o impede de tornar-se sujeito desta e realizar ultrapassagens. Assim, é o universo subjetivo do ser humano que engendra símbolos, num proceder ativo em que há um poder criador na intenção imaginária, ligada à afetividade e à dimensão simbólica, que se expressa no poder das representações que se articula com a eficácia funcional da linguagem, que viabiliza a expressão de laços sociais mais satisfatórios.

Depreende-se das análises dos textos dos discursos dos sujeitos, ou seja, das coincidências, das representações que incidem juntas, as seguintes reflexões: O sujeito confusionado com o objeto estabelece uma relação dual imaginária. Indicando um colamento entre o enfermeiro e a enfermagem, uma transitividade e a ausência de elementos que venham mediatizar esse eu e 0 outro. Um não consegue reconhecer o outro via um significante simbólico. Há uma sutura e pela não existência de espaços, para a ocorrência de representações significantes, não há um reconhecer sobre o conhecimento conhecido. $O$ enfermeiro é a enfermagem e a enfermagem é o enfermeiro.

Essa fusão, essa indistinção é geradora de angústia, de sofrimento, uma 
vez que presentifica o sujeito atrofiado, que pode se imobilizar perdendo a capacidade de emitir um sentido que faça sentido para si. Existe nesta posição apenas signos, um sinal de economia; e o sujeito nessa completude imaginária refere-se ao objeto de desejo como ao próprio desejo. O sujeito capturado no discurso do outro se vê privado da possibilidade de interrogar o significante. Quais são as suas questões? O sentido que vigora já está dado. E vemos isso nas seguintes enunciações reveladoras nos discursos dos enfermeiros: "A confusão, a mistura, o sem limite, o muito abrangente, o tudo, o todo, o muito amplo, o universo. Ninguém sabe o que esperar dele. Nem ele sabe 0 que é enfermeiro. Nem o papel dele dentro da instituição hospitalar. Ele não sabe que profissional ele quer ser".

Por desconhecer-se no seu desejo, o mesmo se apresenta como desejo do desejo do outro, como no movimento primeiro do aparecimento do desejo. Desejo imaginário, sem contorno, que sustenta um objeto fálico, detentor de um poder, de um ter para doar, possuidor imaginariamente do objeto, sem falta. Para sustentar essa posição, o sujeito mantém o grande Outro onipotente, não barrado, equivalente ao seu desejo e no qual aliena o seu desejo. Instituindose nessa posição numa farsa para constituir-se como sujeito desejante. Esse desejo do outro sem lei, que só conhece e reconhece a sua própria lei, mergulhado numa grandeza, numa potência imaginária e que se apresenta caprichoso, arbitrário, imperativo, tirano que lhe demanda nada menos que tudo, a sua vida. Assim, esse grande Outro pede sempre, solicita, ordena, manda, quer que ele faça tudo, que dê respostas a solicitações diversas e abrangentes, que providencie todas as coisas, ou seja, que o enfermeiro tenha uma presença como objeto, sem saber o que representa no desejo desse outro, tornando-se invisível como sujeito. Esse grande outro que se irrita quando o enfermeiro demonstra conhecimento científico (ordem simbólica), quando questiona, situação na qual não será bem-visto nem bem-vindo.

Nessa redução do sujeito a objeto de desejo do outro, nesse estado de carência de significantes, nesse apagamento, introduz-se a dor, à medida que ser nada quando se espera ser alguém, é um desprazer insuportável; e ser nada e ainda ser mandado é mais doloroso, e o sujeito se vê lançado numa indizível frustração. Como o sujeito se esfumaça, se esgarça diante desse grande Outro tirano, que não se importa com suas expectativas, com suas representações, mas que é sustentado pelo sujeito, visto onipotente, sem falta, não existem aberturas para que o imaginário possa se articular com o simbólico de maneira diversa. Fica-se na repetição do mesmo, isto é, na concretude da lei, na sua aspereza e aridez.
Nesse estado de sofrimento o sujeito não se representa no mundo do discurso, apenas se apresenta, se manifesta fora do significante, faz laço no Outro. Machuca-se; deprime-se; desinteressa-se e desmotiva-se. Tudo vai mal, há um mal estar e nada funciona. O enfermeiro busca um sentido para se representar por meio de uma subversão da representação via linguagem, via uma metáfora, nomeando-se pela impotência, como vítima; ou pelo excesso de potência, como vitimado, posições geradoras de medo do fracasso, de insucesso. Individualiza-se no contexto da enfermagem aderindo ou fugindo ao discurso cuja expressão não lhe permite representar-se como sujeito e, por não se achar implicado ali o desejo como significante do próprio sujeito, não consegue decifrá-lo, não consegue imprimir nada dele mesmo na atividade que desempenha, não se exprime.

Diante das co/incidências que se apreendem das representações dadas pelos enfermeiros sobre eles mesmos e sobre a enfermagem, representações ainda incipientes, pois, pouca sustentação oferece aos sujeitos, mas consideramos que não existe nada que seja humano que não seja pensado, sendo o pensamento algo interior, e se ele constrói pontes, acessos, se ele se abre, se dá e recebe se, em uma palavra, ele se comunica o faz dentro de um universo simbólico articulado ao imaginário e ao real da sua subjetividade. É nessa expressão humana, como capacidade do sujeito de apostar no seu desejo e, em si, como possibilidade de constituir-se, de romper com a repetição do "natural", do "habitual", do "sempre foi assim", da enfermagem "é isso mesmo", "um tudo", e do enfermeiro como aquele que "tem de dar conta desse tudo" que, algumas vezes, se traduz num nada, pode-se introduzir nessa seqüência representações que consiga referenciá-lo.

Creio que o enfermeiro não fugindo ao seu compromisso, à sua vocação e sendo o seu objeto constituído nos limites do biológico, do psicológico e do social continua a ter pela frente o desafio de se inserir socialmente como aquele que detém um conhecimento de uma ciência, com uma prática teórica investigativa, compreendendo e interpretando os seus determinantes históricos e sociais, não somente a sua produção social, mas especificamente a sua organização e inserção social, buscando a reestruturação de suas coordenadas, trazendo para o seu interior, as dimensões imaginária, simbólica, ética e política, entrelaçadas o que indubitavelmente revitalizará o seu discurso enquanto práxis social. Consciente de que é o "discurso do sujeito que faz laço social" (Lacan), são as suas buscas de e para um sentido o que, ao mesmo tempo, nos tira do engodo da estabilidade e nos incomoda, o que corresponde a uma necessidade: a de pensar, e a um desejo: o prazer de criar.

\section{REFERÊNCIAS}

1. Garcia-Roza LA. Freud e o inconsciente. $4^{\mathrm{a}}$ ed. Rio de Janeiro (RJ): Zahar; 1988.

2. Lacan J. O Seminário - o eu na teoria de Freud e na técnica da psicanálise. Livro2. 2a ed. Rio de Janeiro (RJ): Zahar; 1987.

3. Safouan M. Seminário: Angústia - Sintoma - Inibição. $2^{\text {a }}$ ed. Campinas (SP): Papirus; 1989.

4. Freud S. Edição Standard Brasileira das Obras Completas. Vol I. Rio de Janeiro (RJ): Imago; 1987.

5. Freud S. Edição Standard Brasileira das Obras Completas. Vol. XIV. Rio de Janeiro (RJ): Imago; 1987.

6. Freud S. Edição Standard Brasileira das Obras Completas. Vol. XVIII. Rio de Janeiro (RJ): Imago; 1987.

7. Freud S. Edição Standard Brasileira das Obras Completas. Vol. XX. Rio de Janeiro (RJ): Imago; 1987.

8. Lacan J. O Seminário - os escritos técnicos de Freud. Livro 1. Rio de Janeiro (RJ): Zahar, 1986.
9. Lacan J. O Seminário - os quatros conceitos fundamentais da psicanálise. Livro 11. $3^{\mathrm{a}}$ ed. Rio de Janeiro (RJ): Zahar; 1988.

10. Dor J. Introdução à leitura de Lacan - 0 inconsciente estruturado como linguagem. $3^{3}$ ed. Porto Alegre (RS): Artes Médicas; 1992.

11. Spink MJP. Gimenes MGG. Práticas discursivas e produção de sentido: Apontamento metodológico para a análise de discurso sobre a saúde e a doença. Saúde e Sociedade 1994; 3(2): 149-69.

12. Kristeva J. História da Linguagem. São Paulo (SP): Ática; 1969.

13. Benvéniste E. Problemas de lingüística geral. São Paulo (SP): Pontes; 1988.

14. Spink MJP. Desvendando as teorias implícitas: uma metodologia de análise das representações sociais. In: Guareschi P, Jovchelovitch $\mathrm{S}$. Textos em representações sociais. Petrópolis (RJ): Vozes; 1994.

15. Freud S. Edição Standard Brasileira das Obras Completas. Vol. XII. Rio de Janeiro (RJ): Imago; 1987. 


\section{ANEXOS}

\begin{tabular}{|c|c|c|c|}
\hline OBJETO & PRIMEIRA ASSOCIAÇÃO & ASSOCIAÇÕES SECUNDÁRIAS & ASSOCIAÇÕES/QUALIFICADORES \\
\hline $\begin{array}{l}\text { O que eu gostaria de saber é o que } \\
\text { Ihe vem à mente quando eu falo a } \\
\text { palavra enfermeira }\end{array}$ & $\begin{array}{l}\text { "Ai, prá mim é muito abrangente } \\
\text { porque há quinze anos que eu sou... } \\
\text { é uma vida prá mim já. Eu não sei } \\
\text { fazer mais nada, eu sei ser } \\
\text { enfermeira. É toda minha vida. Foi só } \\
\text { tentar ser uma boa enfermeira o } \\
\text { tempo todo". }\end{array}$ & $\begin{array}{l}\text { "Lógico, que eu não sei fazer outra } \\
\text { coisa". } \\
\text { "E muitas horas de trabalho da minha } \\
\text { vida, já faz parte da minha vida". } \\
\text { "Na saúde, a gente tem que trabalhar } \\
\text { muito porque pagando mal, a gente } \\
\text { trabalha muito". }\end{array}$ & $\begin{array}{l}\text { (Pausa inicial) } \\
\text { (Risos) } \\
\text { "Esses, quinze anos de vida foi só } \\
\text { dedicado à profissão'. } \\
\text { "Eu falo assim que eu mal sei lavar } \\
\text { roupa (risos) cuidar de casa, cuidar } \\
\text { dos filhos". }\end{array}$ \\
\hline $\begin{array}{l}\text { Como é isso de ser uma boa } \\
\text { enfermeira enquanto valor de vida, } \\
\text { algo vital. }\end{array}$ & $\begin{array}{l}\text { "É... é de vida igual você "tá" falando, } \\
\text { é, geralmente, a gente vai frustrando } \\
\text { muito a expectativa". } \\
\text { "Mas, me é exigido outras coisas que } \\
\text { eu acho que não tem a ver comigo } \\
\text { nem que seja minha função. É } \\
\text { exigido, quase que, o todo". }\end{array}$ & $\begin{array}{l}\text { "É exigido do enfermeiro ser quebra- } \\
\text { galho do hospital, te cobra um milhão } \\
\text { de coisas'. } \\
\text { "Eu queria ser aquela pessoa que } \\
\text { dissemos assim: olha, eu preciso } \\
\text { dela para isso aqui, isso aqui que é a } \\
\text { função dela, sem ela não seria feito". } \\
\text { "Na realidade você vê que ninguém } \\
\text { sabe o que é que ele tem de esperar } \\
\text { de mim enquanto enfermeiro'. }\end{array}$ & $\begin{array}{l}\text { "A gente está querendo ser um } \\
\text { profissional que me agrade, que eu } \\
\text { faça aquilo que eu gosto de fazer e } \\
\text { que é da minha profissão'. } \\
\text { "Isso me frustra". } \\
\text { 'Ter que dar respostas a solicitações } \\
\text { diversas e abrangentes, me frustra". } \\
\text { "Sua função dentro do hospital } \\
\text { tornou-se muito abrangente e está } \\
\text { muito misturado'. }\end{array}$ \\
\hline $\begin{array}{l}\text { Mas, você exerce uma função } \\
\text { administrativa. }\end{array}$ & $\begin{array}{l}\text { "Que é só minha, e não abro não } \\
\text { dela, e se alguém começar a querer } \\
\text { fazê-la, eu viro uma fera". }\end{array}$ & $\begin{array}{l}\text { "Eu vou falar o termo corriqueiro, } \\
\text { você é a chefe do auxiliar, ele é meu } \\
\text { funcionário". } \\
\text { "Então, ele é meu, não importa". } \\
\text { "Eles falam que eu não tenho } \\
\text { críticas, que eu não aceito críticas'. }\end{array}$ & $\begin{array}{l}\text { "Ensina, orienta, que supervisiona a } \\
\text { técnica dele, que de fato avalia, se } \\
\text { alguém faz isso, eu viro uma fera'. } \\
\text { "Já basta eu ter que fazer coisas que } \\
\text { não é da minha função, se alguém } \\
\text { faz o que é da minha função eu viro } \\
\text { uma fera". }\end{array}$ \\
\hline
\end{tabular}

Quadro 1. Mapas de associações de idéias. 


\begin{tabular}{|c|c|c|}
\hline Quem é o enfermeiro? & 0 que é Enfermeiro? & 0 que é a Enfermagem? \\
\hline 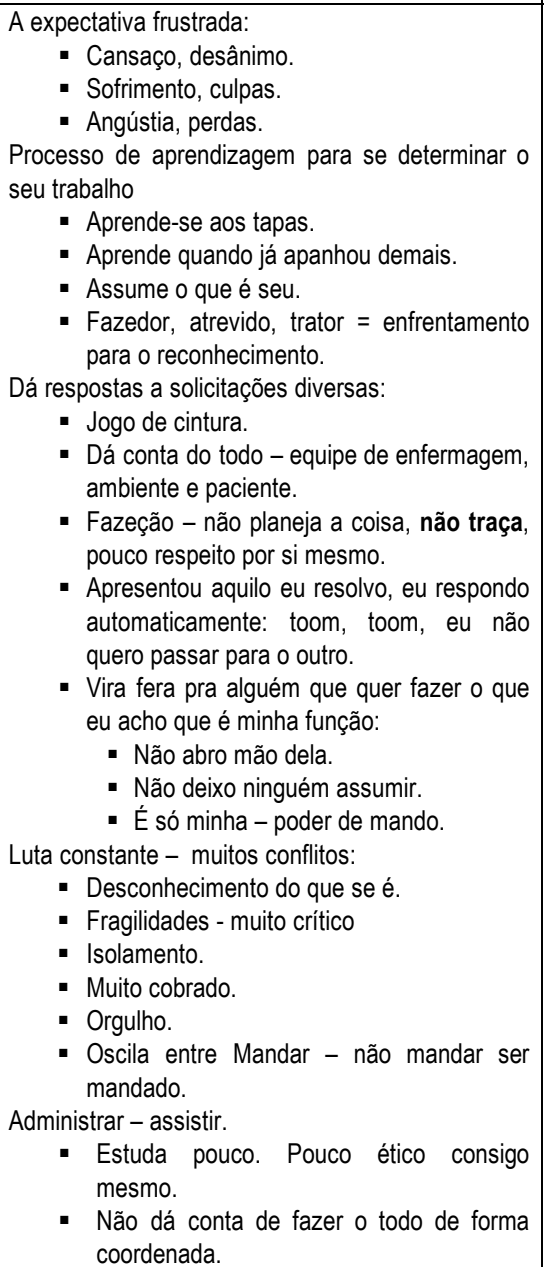 & $\begin{array}{l}\text { Algo muito abrangente: } \\
\text { - Minha vida - tentar ser um bom } \\
\text { enfermeiro. } \\
\text { - Tarefa pouco grandiosa aos olhos dos } \\
\text { outros. } \\
\text { - Não sei fazer outra coisa. } \\
\text { - Perfil indeterminado. } \\
\text { Quebra-galho: } \\
\text { - Função muito misturada - falta } \\
\text { determinação. } \\
\text { - Serviçal - servir - servidor - auxiliar } \\
\text { Chefe do auxiliar de enfermagem: } \\
\text { - Cargo } \\
\text { - Poder de mando - arma para } \\
\text { reconhecimento/ liderança. } \\
\text { Faz tudo e estar em todos os lugares: } \\
\text { - Espírito } \\
\text { - Mulher maravilha } \\
\text { - Tarefeira } \\
\text { Ninguém sabe o que é que tem de esperar dele. } \\
\text { Ninguém sabe definir porque é que precisa dele. } \\
\text { Os outros não conseguem enxergar. } \\
\text { Trabalho pouco evidenciado. } \\
\text { Atrevido. } \\
\text { Existe em função do paciente. } \\
\text { Pouco pode evidenciar o seu conhecimento } \\
\text { científico - fica apagado. }\end{array}$ & $\begin{array}{l}\text { Equipe } \\
\text { - Todos que trabalham comigo } \\
\text { - Toda a minha equipe de enfermagem } \\
\text { feminina } \\
\text { Profissão muito sofrida. } \\
\text { Processo de escravidão: } \\
\text { - Muitas cobranças. } \\
\text { - Muito mandada - todos mandam até o } \\
\text { - paciente. } \\
\text { - Falta de determinação do que se é. } \\
\text { (quem não sabe é criticado por quem não } \\
\text { sabe -saída para a frustração -critico a } \\
\text { mim mesmo sem saber). } \\
\text { Não enfrenta os seus fantasmas. } \\
\text { Luta constante: } \\
\text { - Pouca identidade enquanto grupo } \\
\text { - Isolamento } \\
\text { - Depreciação } \\
\text { - Sofrimento } \\
\text { - Sentimento de culpa. } \\
\text { Enfermagem/Enfermeiro } \\
\text { - Escolha não consciente } \\
\text { - Não sabe que profissional quer ser } \\
\text { - Sabe que não pode ser outra coisa } \\
\text { - Não sabe o que é ser enfermeiro } \\
\text { - Trabalho para o sustento da família } \\
\text { - Orgulho de ser } \\
\text { - grandioso. }\end{array}$ \\
\hline
\end{tabular}

Quadro 2. Representações do Enfermeiro e da Enfermagem - Prática Discursiva. 